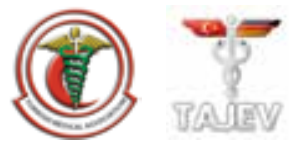

\title{
Methods for endometrial preparation in frozen-thawed embryo transfer cycles
}

\author{
Ziya Kalem¹, Müberra Namlı Kalem², Timur Gürgan ${ }^{1}$ \\ ${ }^{1}$ Gürgan Clinic IVF Center, Ankara, Turkey \\ ${ }^{2}$ Department of Obstetrics and Gynecologoy, Turgut Özal University School of Medicine, Ankara, Turkey
}

\begin{abstract}
Frozen-thawed (FT) embryo transfer is a procedure used for the storage and transfer of excess embryos obtained during in vitro fertilizationintracytoplasmic sperm injection cycles. In recent years, improvements in laboratory conditions and limitations on the number of embryos to be transferred have led to a progressive increase in FT embryo transfer cycles. However, the best solution for endometrial preparation in these cycles is still a matter of debate.

In this study, we aimed to review the current methods of endometrial preparation in FT embryo transfer cycles. In light of the current literature, it is hard to determine which method is the best for endometrial preparation. It is therefore necessary to conduct randomized controlled studies in a prospective design, which will also evaluate the above-mentioned factors. (J Turk Ger Gynecol Assoc 2016; 17: 168-71)
\end{abstract}

Keywords: Thawing, embryo cryopreservation, endometrial preparation, frozen-thawed embryo transfer, transdermal estradiol

Received: 31 December, 2015 Accepted: 14 July, 2016

\section{Introduction}

Frozen-thawed (FT) embryo transfer is a procedure used for the storage and transfer of excess embryos obtained during in vitro fertilization (IVF)-intracytoplasmic sperm injection (ICSI) cycles. In recent years, improvements in laboratory conditions and limitations on the number of embryos to be transferred have led to a progressive increase in FT embryo transfer cycles. Another preferred practice to prevent multiple pregnancies in IVF cycles is to transfer a single embryo and freeze all surplus embryos (1). However, the best solution for endometrial preparation in these cycles is still a matter of debate (2).

Frozen-thawed embryo transfer prevents embryo waste and increases the probability of pregnancy in a single stimulated cycle. Protocols applied in FT cycles aim for endometrial preparation only and are therefore simpler than complicated protocols that aim to develop many follicles. As the treatment for subfertility increases, so does the importance of FT embryo transfer; however, there is no consensus about which method is the best $(3,4)$.

Pregnancy rates following FT embryo transfer have been found to be higher than those following fresh embryo transfer (5). Further, FT embryo transfer increases the cumulative pregnancy rate and decreases the cost; in addition, it is easy to perform and can be applied in a shorter time duration when compared to repetitive fresh embryo transfers (5). Using frozen excess embryos obtained as a result of the time-totime implementation of in vitro maturation (IVM) in patients with polycystic ovaries, successful pregnancies have been achieved (6). Therefore, studies have concentrated on factors affecting the success rate of FT embryo transfer cycles.
Various cycle protocols are used for the preparation of the endometrium in an FT embryo transfer cycle. In one of these procedures, the transfer time is determined either by the natural course of a cycle [i.e., in an ovulatory patient exhibiting a natural (spontaneous) cycle] or by inducing ovulation during the course of a natural cycle. The second procedure involves the artificial preparation of the endometrium through the administration of exogenous estrogen and progesterone, which can be performed with or without the association of a gonadotropin-releasing hormone agonist. In the third procedure, the cycle is stimulated by gonadotropins and ovulation is induced by recombinant-human chorionic gonadotropin ( $\mathrm{r}$ $\mathrm{Hcg}$ ) or hCG; however, this practice is no longer applied $(7,8)$.

Embryo transfer in a natural (spontaneous) cycle

Both embryo and endometrial development have to be synchronized in FT embryo transfer cycles in order to maximize the pregnancy rate (9). This synchronization can be achieved in several ways. The easiest is the endocrinological preparation of the endometrium during the natural cycle using the patient's own follicular sex steroids. In this application, the timing for embryo transfer (ET) is determined by either investigating the spontaneous luteinizing hormone (LH) surge or by the administration of exogenous human chorionic gonadotrophin (hCG) to start luteinization (10). Success of the natural cycle depends on the accurate determination of the ovulation time and the precise estimation of endometrial receptivity $(11,12)$.

Thawing and transfer procedures have to be performed during this receptive period. In the FT cycles performed during a natural cycle, urine or blood LH level is regularly analyzed and followed up. Ovulation is estimated to occur 36 to 40 hours 
after the determination of the blood LH surge (13). Urine LH increases 21 hours after the detection of the blood LH surge, and this fact has to be taken into consideration when interpreting the increase in urine LH (14).

Another problem in determining the time of the spontaneous LH surge is the variability of this increase, both among cycles and patients (15). At least one measurement, and preferably two measurements, has to be performed daily in order to accurately determine the $\mathrm{LH}$ surge. The threshold values of urine $\mathrm{LH}$ kits are highly variable, corresponding to an approximately $30 \%$ risk of a false-negative result; furthermore, patients state that it is hard to interpret the test results (16).

In order to avoid the difficulties of LH follow-ups, ovulation is frequently triggered by the administration of hCG during natural cycles; this is called the modified natural cycle. This approach does not require $\mathrm{LH}$ measurement, but the development of a dominant follicle has to be regularly investigated and followed up with ultrasonography (USG) in order to determine the suitable time for hCG administration (17). When the dominant follicle has sufficiently matured and has reached the proper size (17-18 mm), hCG is administered to the patient for the final oocyte maturation and ovulation. Ovulation occurs about 36 to 38 hours after hCG administration (13). The administration of hCG to induce ovulation in a natural cycle (or modified natural cycle) has been reported to negatively affect the rates for ongoing pregnancies (14.3\% vs 31.1\%) (18).

In natural or modified natural cycles, the embryo transfer is performed three to five days after ovulation, depending on when the embryos were frozen (19).

Ovulation may occur unexpectedly while planning a natural cycle, which can lead to difficulties in adjusting the time of thawing and transferring the embryos. When an unexpected early ovulation occurs, the cycle is generally cancelled. In a study by Weissman et al. (20), the LH surge was determined on the day of hCG administration during a modified natural cycle, and the cycle had to be cancelled. However in previous studies, an LH surge on the day of hCG administration was shown not to exert any negative effect $(21,22)$.

In most studies related to natural cycle applications, USG and the evaluation of estradiol, progesterone, and LH levels were used in combination in order to determine the time of thawing and transferring the embryos. With regard to timing, this approach is more reliable, but it is expensive and problematic. Alternatively, the follow-up of the LH surge, using urine LH kits, is an easier and more straightforward method; however, it carries with it a higher risk of a faulty test result. Cycle cancellation may be inevitable in $7 \%$ to $12 \%$ of natural cycles due to undetected ovulation (18).

Fewer laboratory analyses and USG follow-ups are required for determining the time of hCG administration in the modified natural cycle, and it is therefore less troublesome for both the physician and the patient. In studies comparing the natural cycle with the modified natural cycle, no marked differences were determined between the two procedures with regard to clinical pregnancy, ongoing pregnancy, and live births $(20,23)$. In two studies investigating the effects of luteal support in the natural cycle, luteal support was shown not to affect the results with regard to clinical pregnancy (Odds ratio (OR) 0.80, 95\% confidence interval (CI) 0.61-1.0 vs OR 1.1, 95\% CI 0.79-1.5). However, luteal support was shown to positively affect the results relating to a pregnancy continuing (OR $1.5,95 \%$ CI $0.58-4.0$ vs OR 0.82, 95\% CI 0.62-1.1) (20, 24).

\section{Artificial endometrium preparation by the exogenous} administration of estrogen-progesterone

Another frequently used method for endometrium preparation is with the exogenous administration of estrogen and progesterone (with or without a gonadotrophin-releasing-hormone (GnRH) agonist), also called the artificial cycle, and is frequently used as an alternative for the natural cycle. Rates of clinical pregnancy and chemical pregnancy were shown not to differ in artificial cycles with regard to the administration of a GnRH agonist (25).

In order to mimic the endocrine conditions of the endometrium of a normal cycle in an artificial cycle, estrogen and progesterone are administered consecutively. Estrogen administration is started at the beginning of the cycle, causing endometrial development while suppressing dominant follicle development. Estradiol is introduced before the fourth day of the cycle. The earlier estradiol is commenced, the less the risk there is of unwanted follicular development and ovulation. Estrogen administration is continued until the endometrium reaches a thickness of $8 \mathrm{~mm}$ (determined using an ultrasonographic examination), and progesterone is then combined to initiate the secretory changes. Thus, an attempt is made to mimic the physiologic mid-cycle estrogen-progesterone transition $(26,27)$.

Estrogen can be administered as an oral tablet, transdermal plaster, or transvaginal ring. The most widely used forms are oral micronized estradiol or transdermal estradiol. Serum estradiol levels and endometrial thickness were not found to differ between these two applications (28). Some of the orally administered estradiol valerate is converted to estrone in the intestinal system (29). Estradiol and estrone are then transferred to the liver via the portal system, and converted there to estriol. During this transportation process, circulatory estrogen activity decreases by $30 \%$ (30).

The commonly used forms are currently estradiol valerate and micronized estrogens. Estradiol valerate (Progynova, Shering; Berlin, Germany) is administered throughout the cycle as follows: $1 \mathrm{mg}$ on days 1 to $5,2 \mathrm{mg}$ on days 6 to $9,6 \mathrm{mg}$ on days 10 to $13,2 \mathrm{mg}$ on days 14 to $17,4 \mathrm{mg}$ on days 18 to 26 , and $1 \mathrm{mg}$ on days 27 and 28 (31) (Figure 1).

Estrogen can also be administered by the transdermal route, meaning it cannot be metabolized in the liver, which results in estradiol valerate concentrations exceeding those of estrone. In other words, a more physiological estradiol/estrone ratio (approximately 1) exists. When estrogen is administered orally, this ratio is 0.2 , and therefore is not in accordance with the physiological values (32).

Transdermal estrodiol valerate (Estraderm, CIBA Pharmaceutical Co.; Summit, NJ, USA) plasters are applied on the lower abdominal region, whereby between day 1 and 6 of the cycle, plasters are applied as a dose of 50 micrograms once every three days; between day 7 and 9, one plaster of 100 micrograms; on days 10 and 11, a 200 microgram plaster; and between day 12 and 14, four plasters, each of 100 micrograms (400 micrograms total) are used. Between day 15 and 17, the dose is decreased to 100 micrograms, but is then increased again to 200 micrograms between day 18 and 28 of the cycle. In this protocol, an estradiol concentration exceeding $200 \mathrm{pg} / \mathrm{mL}$ is accepted to be sufficient (33). However, transdermal estrogen application can cause fluctuations in estrogen concentrations, and it may sometimes be difficult to maintain a constant steroid level. Another reason for preferring the transdermal route to oral administration is the unchanged serum lipid levels, coagulation factors, and renin substrate (34). 


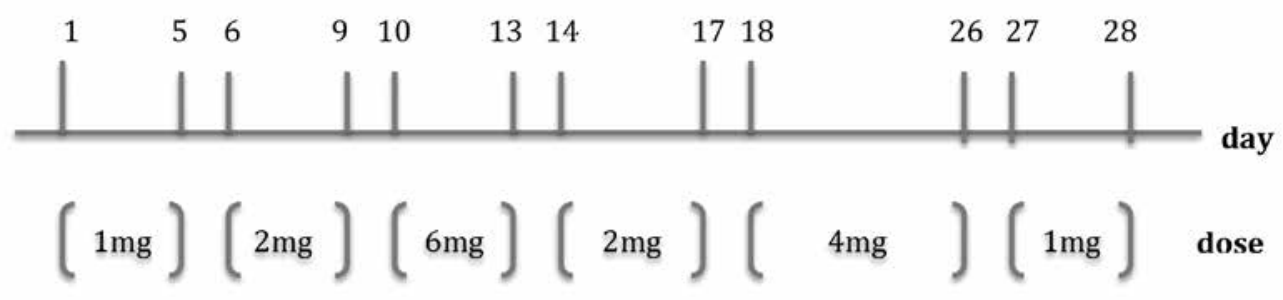

Figure 1. Doses and days of estrogen in the artificial cycle. This figure shows the days and doses of estrogen administration in patients with an artificial endometrial preparation.

Pregnancy rates were not found to differ between oral and transdermal administration (35). However, transvaginal estrogen reaches only $25 \%$ of the circulatory level of the same dose of estrogen administered orally; furthermore, it damages the effect of the vaginal progesterone used for luteal support, making transvaginal estrogen a less favored application (36).

Progesterone can either be administered in artificial cycles using the intramuscular route, or as vaginal suppositories or vaginal gels. With regard to the pregnancy rates in donor cycles, Glujovsky et al. (37) could not detect any difference between vaginal and intramuscular administration. The starting time for progesterone administration depends on endometrial thickness but not on the duration of estrogen administration. Progesterone administration can only be commenced when the endometrium thickness exceeds $8 \mathrm{~mm}(38,39)$.

Natural progesterone (Federa, Sterop; Brussels, Belgium) or micronized progesterone (Utrogestan, Piette; Brussels, Belgium) are the most generally used progesterone preparations. The administration of natural progesterone is commenced intramuscularly in a dose of $50 \mathrm{mg}$ on day 14 of the cycle, and is continued in a dose of $100 \mathrm{mg}$ daily between days 15 and 26 . Micronized progesterone is administered vaginally in a dose of $100 \mathrm{mg}$ or $200 \mathrm{mg}$ on day 14 of the cycle, and is continued in a dose of $300 \mathrm{mg}$ or $600 \mathrm{mg}$ daily between days 15 and 26 (40).

Orally administered micronized progesterone was shown not to be suitable for preparing the endometrium for implantation. None of the biopsy investigations was observed to be compatible in this respect (41). Vaginal progesterone was determined to form a secretory phase of endometrium that resembles that of the natural cycle (42). In intramuscular progesterone administration, $43 \%$ of the endometria cases were found to be in accordance with the cycle phase; in the rest of the cases, increased asynchronous maturation was detected (43).

In artificial preparation, the time for thawing and transferring the embryos is planned according to the commencement of progesterone support. The exogenous administration of estrogen and progesterone does not guarantee the complete suppression of the pituitary gland; in other words, a dominant follicle may develop. The developing follicle may also undergo spontaneous luteinization, which leads to the early exposure of the endometrium to progesterone, and thus incorrect calculations for thawing and transfer times. For these reasons, GnRH agonists can be added to the treatment protocols in order to downregulate the pituitary, thus preventing follicular development. Both of the artificial cycles are less physiological due to exogenous drug administration; however, they are practical and easy to apply, and hence preferred both by physicians and patients. However, with regard to overall ongoing pregnancy rates, it has not yet been totally clarified which procedure offers the superior method (44). Table 1 shows the alternative estrogen and progesterone application methods.

\section{Which method is preferable?}

When eight retrospective studies, including 8152 cycles, and one randomized controlled study including 111 cycles were investigated in the literature, no differences were observed between the natural cycles and artificial cycles with regard to clinical pregnancy (OR 1.2, 95\% CI 0.86-1.6), ongoing pregnancy (OR 1.2, 95\% CI 0.95-1.5), or live births (OR 1.2, 95\% CI 0.93-1.6) (45). In four studies comparing natural cycles with GnRH agonist-supported artificial cycles, clinical pregnancy and live births did not differ (46, 47-49). Furthermore, clinical pregnancy was determined not to differ between the artificial cycles and GnRHsupported artificial cycles $(44,50,51)$.

Some studies have shown that endometrial thickness positively affects pregnancy rates in FT cycles $(39,52,53)$. Complete downregulation cannot be guaranteed in artificial cycles, and early luteinization may therefore exist in $5 \%$ of cases. Estradiol levels are higher in the artificial cycles than in natural cycles, and consequently, the endometrium has been reported to be thicker in the artificial cycles (30); however, in some studies, such a difference has not been detected (54). Non-physiologically high estradiol levels have been claimed to cause endometrial damage and variances in the implantation window (55). Broadly, this is the main problem in IVF applications. If this claim were taken into account, low pregnancy rates would be expected in the artificial cycles because of high $\mathrm{E}_{2}$ levels. However, such a negative effect has not been shown in the artificial cycles, and this claim of a negative effect needs to be investigated in further studies.

Pregnancy rates do not differ between the natural and artificial cycles; therefore, laboratory conditions, social status, and physicians' and patients' preferences are effective for making a decision in the choice between these two procedures. In a study by Gelbaya et al. (56), the natural cycles and downregulated artificial cycles did not differ from each other in this respect.

Clinical pregnancy, ongoing pregnancy, and live birth rates have not been found to differ between endometrial preparations induced by human menopausal gonadotrophin (HMG) or by exogenously administered estrogen-progesterone in patients with polycystic ovary syndrome (PCOS) or those with anovulation; however, a thin endometrium was more frequently observed in HMG-induced cycles $(57,58)$.

Some studies have shown that long-term GnRH agonist administration before IVF/ICSI in infertile women with endometriosis or adenomyosis significantly increases the chances of pregnancy (59). It may be true for FT embryo transfer cycles. In a study 
Table 1. Alternative ways of administering estrogen and progesterone

\begin{tabular}{|c|c|c|c|c|c|c|c|}
\hline & & \multicolumn{6}{|c|}{ Dose/Days of Cycle } \\
\hline \multirow[b]{2}{*}{ 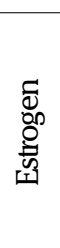 } & Oral (daily) & $\begin{array}{l}1 \mathrm{mg} \\
(1-5)\end{array}$ & $\begin{array}{l}2 \mathrm{mg} \\
(6-9)\end{array}$ & $\begin{array}{c}6 \mathrm{mg} \\
(10-13)\end{array}$ & $\begin{array}{c}2 \mathrm{mg} \\
(14-17)\end{array}$ & $\begin{array}{c}4 \mathrm{mg} \\
(18-26)\end{array}$ & $\begin{array}{c}1 \mathrm{mg} \\
(27-28)\end{array}$ \\
\hline & $\begin{array}{l}\text { Transdermal } \\
\text { (patch) } \\
\text { once every } 3 \\
\text { day }\end{array}$ & $\begin{array}{l}50 \mu \mathrm{g} \\
(1-6)\end{array}$ & $\begin{array}{c}100 \mu \mathrm{g} \\
(7-9)\end{array}$ & $\begin{array}{c}200 \mu \mathrm{g} \\
(10-11)\end{array}$ & $\begin{array}{c}400 \mu \mathrm{g} \\
(12-14)\end{array}$ & $\begin{array}{l}100 \mu \mathrm{g} \\
(15-17)\end{array}$ & $\begin{array}{c}200 \mu \mathrm{g} \\
(18-28)\end{array}$ \\
\hline \multirow{3}{*}{ 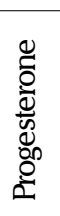 } & $\begin{array}{l}\text { Intravaginal } \\
\text { (daily) }\end{array}$ & & & \multicolumn{2}{|c|}{$\begin{array}{c}100 \text { or } 200 \mathrm{mg} \\
\text { (14) }\end{array}$} & \multicolumn{2}{|c|}{$\begin{array}{l}300 \text { or } 600 \mathrm{mg} \\
(15-26)\end{array}$} \\
\hline & $\begin{array}{l}\text { Intramuscular } \\
\text { (daily) }\end{array}$ & & 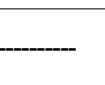 & \multicolumn{2}{|c|}{$\begin{array}{r}50 \mathrm{mg} \\
(14)\end{array}$} & \multicolumn{2}{|c|}{$\begin{array}{l}100 \mathrm{mg} \\
(15-26)\end{array}$} \\
\hline & Oral & \multicolumn{4}{|c|}{ Inefficient } & & \\
\hline
\end{tabular}

involving patients administered a GnRH agonist combined with estrogen and progesterone, clinical pregnancy, implantation, and ongoing pregnancy rates were $51.35 \%, 32.56 \%$, and $48.91 \%$, respectively, which were significantly higher than the rates in patients administered only estrogen and progesterone $(24.83 \%$, $16.07 \%$, and $21.38 \%$, respectively) (60).

Briefly, in light of the current literature, it is difficult to determine which method is better for endometrial preparation. All current procedures appear to be equally successful with regard to ongoing pregnancy rates. Most studies are retrospective, and this may lead to prejudice during the comparisons. The preferences of patients and the impact of costs have not been taken into consideration during studies. Therefore, it is necessary to conduct randomized controlled studies in a prospective manner, which should also evaluate the above-mentioned factors.

Ethics Committee Approval: N/A.

Informed Consent: N/A.

Peer-review: Externally peer-reviewed.

Author Contributions: Concept - Z.K., M.N.K.; Design - Z.K., M.N.K.; Supervision - T.G., Z.K.; Resources - Z.K., M.N.K.; Data Collection and/or Processing - Z.K., M.N.K.; Analysis and/or Interpretation - Z.K., T.G.; Literature Search - Z.K., M.N.K.; Writing Manuscript - Z.K.; Critical Review - T.G.; Other - M.N.K.

Conflict of Interest: No conflict of interest was declared by the authors.

Financial Disclosure: The authors declared that this study has received no financial support.

\section{References}

1. Gurgan T, Demirol A. Why and how should multiple pregnancies be prevented in assisted reproduction treatment programmes? Reprod Biomed Online 2004; 9: 237-44. [Crossref]

2. Le Lannou D, Griveau JF, Laurent MC, Gueho A, Veron E, Morcel K. Contribution of embryo cryopreservation to elective single embryo transfer in IVF-ICSI. Reprod Biomed Online 2006; 13: 368-75. [Crossref]

3. Ghobara T, Vanderkerchove P. Cycle regimens for frozen-thawed embryo transfer. The Cochrane Library 2008. [Crossref]

4. Weissman A, Levin D, Ravhon A, Eran H, Golan A, Levran. What is the preferred method for timing natural cycle frozen-thawed embryo transfer? Reprod Biomed Online 2009; 19: 66-71. [Crossref]

5. Shapiro BS, Daneshmand ST, Garner FC, Aguirre M, Hudson C, Thomas S. Evidence of impaired endometrial receptivity after ovarian stimulation for in vitro fertilization: a prospective randomized trial comparing fresh and frozen-thawed embryo transfer in normal responders. Fertil Steril 96; 2: 344-8. [Crossref]
6. Demirol A, Guven S, Benkhalifa M, Sari T, Gurgan T. Successful birth following transfer of frozen-thawed embryos produced from in-vitro matured oocytes. Reprod Biomed Online 2010; 21: 215-8. [Crossref]

7. Wright KP, Guibert J, Weitzen S, Davy C, Fauque P, Olivennes F. Artificial versus stimulated cycles for endometrial preparation prior to frozen-thawed embryo transfer. Reprod Biomed Online 2006; 13: 321-5. [Crossref]

8. Imbar T, Hurwitz A. Synchronization between endometrial and embryonic age is not absolutely crucial for implantation. Fertil Steril 2004; 82: 472-4. [Crossref]

9. Ming L, Liu P, Qiao J, Lian Y, Zheng X, Ren X, et al. Synchronization between embryo development and endometrium is a contributing factor for rescue ICSI outcome. Reprod Biomed Online 2012; 24: 527-31. [Crossref]

10. Groenewoud ER, Macklon NS, Cohlen BJ. Cryo-thawed embryo transfer: natural versus artificial cycle. A non-inferiority trial (ANTARCTICA trial). BMC Women's Health 2012; 12: 27. [Crossref]

11. Harper MJ. The implantation window. Baillieres Clin Obstet Gynaecol 1992; 6: 351-71. [Crossref]

12. Tabibzadeh S. Molecular control of the implantation window. Hum Reprod Update 1998; 4: 465-71. [Crossref]

13. Andersen AG, Als-Nielsen B, Hornnes PJ, Andersen LF. Time interval from human chorionic gonadotrophin (HCG) injection to follicular rupture. Hum Reprod 1995; 10: 3202-5.

14. Miller PB, Soules MR. The usefulness of a urinary LH kit for ovulation prediction during menstrual cycles of normal women. Obstet Gynecol 1996; 87: 13-7. [Crossref]

15. Park SJ, Goldsmith LT, Skurnick JH, Wojtczuk A, Weiss G. Characteristics of the urinary luteinizing hormone surge in young ovulatory women. Fertil Steril 2007; 88: 684-90. [Crossref]

16. O'Connor KA, Brindle E, Miller RC, Shofer JB, Ferrell RJ, Klein NA, et al. Ovulation detection methods for urinary hormones: precision, daily and intermittent sampling and a combined hierarchical method.Hum Reprod 2006; 21: 1442-52. [Crossref]

17. Sathanandan M, Macnamee MC, Rainsbury P, Wick K, Brinsden P, Edwards RG. Replacement of frozen-thawed embryos in artificial and natural cycles: a prospective semi-randomized study. Hum Reprod 1991; 6: 685-7.

18. Fatemi HM, Kyrou D, Bourgain C, Van den Abbeel E, Griesinger G, Devroey, P. Cryopreserved-thawed human embryo transfer: spontaneous natural cycle is superior to human chorionic gonadotropin-induced natural cycle. Fertil Steril 2010; 94: 2054-8. [Crossref]

19. Paulson RJ. Hormonal induction of endometrial receptivity. Fertil Steril 2011; 96: 530-5. [Crossref]

20. Weissman A, Horowitz E, Ravhon A, Steinfeld Z, Mutzafi R, Golan A, et al. Spontaneous ovulation versus HCG triggering for timing natural-cycle frozen-thawed embryo transfer: a randomized study. Reprod Biomed Online 2011; 23: 484-9. [Crossref]

21. Griesinger G, Weig M, Schroer A, Diedrich K, Kolibianakis EM. Mid-cycle serum levels of endogenous LH are not associated with the likelihood of pregnancy in artificial frozen-thawed embryo transfer cycles without pituitary suppression. Human Reprod 2007; 22: 2589-93. [Crossref] 
22. Groenewoud ER, Kollen BJ, Macklon NS, Cohlen BJ. Spontaneous LH surges prior to HCG administration in unstimulated-cycle frozen-thawed embryo transfer do not influence pregnancy rates. Reprod Biomed Online 2012; 24: 191-6. [Crossref]

23. Chang EM, Han JE, Kim YS, Lyu W, Lee WS, Yoon TK. Use of the natural cycle and vitrification thawed blastocyst transfer results in better in-vitro fertilization outcomes. J Assist Reprod Genet 2011; 28: 369-74. [Crossref]

24. Tomás C, Alsbjerg B, Martikainen H, Humaidan P. Pregnancy loss after frozen-embryo transfer - a comparison of three protocols. Fertil Steril 2012; 98: 1165-9. [Crossref]

25. Nekoo EA, Chamani M, Tehrani ES, Rashidi BH, Tanha FD, Kalantari V. Artificial Endometrial Preparation for Frozen-Thawed Embryo Transfer with or without Pretreatment with Depot Gonadotropin Releasing Hormone Agonist in Women with Regular Menses. J Fam Reprod Health 2015; 9: 1-4.

26. El-Toukhy T, Coomarasamy A, Khairy M, Sunkara K, Seed P, Khalaf $\mathrm{Y}$, et al. The relationship between endometrial thickness and outcome of medicated frozen embryo replacement cycles. Fertil Steril 2008; 89: 832-9. [Crossref]

27. Jaroudi KA, Hamilton C J, Willemsen WN, Sieck UV, Roca G. Artificial endometrial stimulation for frozen embryo replacement. Fertil Steril 1991; 55: 835-7. [Crossref]

28. Hancke K, More S, Kreienberg R, Weiss JM. Patients undergoing frozenthawed embryo transfer have similar live birth rates in spontaneous and artificial cycles. J Assist Reprod Genet 2012; 29: 403-7. [Crossref]

29. Ryan KJ, Engel IL. The interconversion of estrone and estradiol by human tissue slices 1, 2, 3. Endocrinology 1953; 52: 287-91. [Crossref]

30. van Keep PA, Utian WH, Vermeulen A. Potency and hepato-cellular effects of oestrogens after oral, percutaneous, and subcutaneous administration. In The Controversial Climacteric. Springer Netherlands 1982; pp. 103-25. [Crossref]

31. Devroey P, Pados G. Preparation of endometrium for egg donation. Hum Reprod Update 1998; 4: 856-61. [Crossref]

32. Powers MS, Schenkel L, Darley PE, Good WR, Balestra JC, Place VA. Pharmacokinetics and pharmacodynamics of transdermal dosage forms of $17 \beta$-estradiol: comparison with conventional oral estrogens used for hormone replacement. Am J Obstet Gynecol 1985; 152: 1099-106. [Crossref]

33. Chetkowski RJ, Meldrum DR, Steingold KA, Randle D, Lu JK, Eggena P, et al. Biologic effects of transdermal estradiol. N Eng J Med 1986; 314: 1615-20. [Crossref]

34. Powers MS, Schenkel L, Darley PE, Good WR, Balestra JC, Place VA. Pharmacokinetics and pharmacodynamics of transdermal dosage forms of 17 $\beta$-estradiol: comparison with conventional oral estrogens used for hormone replacement. Am J Obstet Gynecol 1985; 152: 1099-106. [Crossref]

35. Rosenwaks Z, Navot D, Veeck L, LIU HC, Steingold K, Kreiner D, et al. Oocyte Donation. Ann NY Acad Sci 1988; 541: 728-41. [Crossref]

36. Stumpf PG. Selecting constant serum estradiol levels achieved by vaginal rings. Obstet Gynecol 1986; 67: 91-4.

37. Glujovsky D, Pesce R, Fiszbajn G, Sueldo C, Hart RJ, Ciapponi A. Endometrial preparation for women undergoing embryo transfer with frozen embryos or embryos derived from donor oocytes. The Cochrane Library 2010. [Crossref]

38. Nawroth F, Ludwig M. What is the 'ideal'duration of progesterone supplementation before the transfer of cryopreserved-thawed embryos in estrogen/progesterone replacement protocols? Hum Reprod 2005; 20: 1127-34. [Crossref]

39. El-Toukhy T, Coomarasamy A, Khairy M, Sunkara K, Seed P, Khalaf Y, et al. The relationship between endometrial thickness and outcome of medicated frozen embryo replacement cycles. Fertil Steril 2008; 89: 832-9. [Crossref]

40. Pados G, Camus M, Van Waesberghe L, Liebaers I, Van Steirteghem A, Devroey P. Oocyte and embryo donation: evaluation of 412 consecutive trials. Hum Reprod 1992; 7: 1111-7.

41. Devroey P, Palermo G, Bourgain C, Van Waesberghe L, Smitz J, Van Steirteghem AC. Progesterone administration in patients with absent ovaries. Int J Fertil 1988; 34: 188-93.
42. Bourgain C, Devroey P, Van Waeshberghe L, Smitz J, Van Steirteghem AC. Effects of natural progesterone on the morphology of the endometrium in patients with primary ovarian failure. Hum Reprod 1990; 5: 537-43.

43. Pados G, Devroey P. Luteal phase support. Assist Reprod Rev 1992; 2: 148.

44. Dal Prato L, Borini A, Cattoli M, Bonu MA, Sciajno R, Flamigni C. Endometrial preparation for frozen-thawed embryo transfer with or without pretreatment with gonadotropin-releasing hormone agonist. Fertil Steril 2002; 77: 956-60. [Crossref]

45. Groenewoud ER, Cantineau AE, Kollen BJ, Macklon NS, Cohlen BJ. What is the optimal means of preparing the endometrium in frozen-thawed embryo transfer cycles? A systematic review and meta-analysis. Hum Reprod Update 2013; dmt030. [Crossref]

46. Al-Shawaf T, Yang D, Al-Magid Y, Seaton A, Iketubosin F, Craft I. Infertility: Ultrasonic monitoring during replacement of frozen/ thawed embryos in natural and hormone replacement cycles. Hum Reprod 1993; 8: 2068-74.

47. Queenan Jr JT, Veeck LL, Seltman HJ, Muasher SJ. Transfer of cryopreserved-thawed pre-embryos in a natural cycle or a programmed cycle with exogenous hormonal replacement yields similar pregnancy results. Fertil Steril 1994; 62: 545-50. [Crossref]

48. TA G, Hunter HR. Cryopreserved-thawed embryo transfer in natural or down-regulated hormonally controlled cycles: A retrospective study. Digest of the World Core Medical Journals (Obstetrics/Gynecology) Z1 2006.

49. Hill MJ, Miller KA, Frattarelli JL. A GnRH agonist and exogenous hormone stimulation protocol has a higher live-birth rate than a natural endogenous hormone protocol for frozen-thawed blastocyst-stage embryo transfer cycles: an analysis of 1391 cycles. Fertil Steril 2010; 93: 416-22. [Crossref]

50. Simon A, Hurwitz A, Zentner BS, Bdolah Y, Laufer N. Transfer of frozenthawed embryos in artificially prepared cycles with and without prior gonadotrophin-releasing hormone agonist suppression: a prospective randomized study. Human Reprod 1998; 13: 2712-7. [Crossref]

51. El-Toukhy T, Taylor A, Khalaf Y, Al-Darazi K, Rowell P, Seed P, et al. Pituitary suppression in ultrasound-monitored frozen embryo replacement cycles. A randomised study. Human Reprod 2004; 19: 874-9. [Crossref]

52. Richter KS, Bugge KR, Bromer JG, Levy MJ. Relationship between endometrial thickness and embryo implantation, based on 1,294 cycles of in vitro fertilization with transfer of two blastocyst-stage embryos. Fertil Steril 2007; 87: 53-9. [Crossref]

53. Kumbak B, Erden HF, Tosun S, Akbas H, Ulug U, Bahçeci M. Outcome of assisted reproduction treatment in patients with endometrial thickness less than $7 \mathrm{~mm}$. Reprod Biomed Online 2009; 18 : 79-84. [Crossref]

54. Tomás C, Alsbjerg B, Martikainen H, Humaidan P. Pregnancy loss after frozen-embryo transfer-a comparison of three protocols. Fertil Steril 2012; 98: 1165-9. [Crossref]

55. Adams SM, Terry V, Hosie MJ, Gayer N, Murphy CR. Endometrial response to IVF hormonal manipulation: Comparative analysis of menopausal, down regulated and natural cycles. Reprod Biol Endocrinol 2004; 2: 21. [Crossref]

56. Gelbaya TA, Nardo LG, Hunter HR, Fitzgerald CT, Horne G, Pease $\mathrm{EE}$, et al. Cryopreserved-thawed embryo transfer in natural or down-regulated hormonally controlled cycles: a retrospective study. Fertil Steril 2006; 85: 603-9. [Crossref]

57. Yu J, Ma Y, Wu Z, Li Y, Tang L, Li Y, et al. Endometrial preparation protocol of the frozen-thawed embryo transfer in patients with polycystic ovary syndrome. Arch Gynecol Obstet 2015; 291: 201-11. [Crossref]

58. Wright KP, Guibert J, Weitzen S, Davy C, Fauque P, Olivennes F. Artificial versus stimulated cycles for endometrial preparation prior to frozen-thawed embryo transfer. Reprod Biomed Online 2006; 13: 321-5. [Crossref]

59. Devlieger R, D'Hooghe T, Timmerman D. Uterine adenomyosis in the infertility clinic. Hum Reprod Update 2003; 9: 139-47. [Crossref]

60. Niu Z, Chen Q, Sun Y, Feng Y. Long-term pituitary downregulation before frozen embryo transfer could improve pregnancy outcomes in women with adenomyosis. Gynecol Endocrinol 2013; 29: 1026-30. [Crossref] 